\title{
Strengthening the Policy Environment for Health Research in the Philippines: Insights from a Preliminary Analysis of Existing Policies
}

\author{
Jaifred Christian F. Lopez, ${ }^{1}$ Reneepearl Kim P. Sales, ${ }^{1}$ Regin George Miguel K. Regis, ${ }^{1}$ \\ Katherine Ann V. Reyes ${ }^{1,2}$ and Beverly Lorraine C. $\mathrm{Ho}^{3}$ \\ ${ }^{1}$ Alliance for Improving Health Outcomes, Quezon City, Philippines \\ ${ }^{2}$ Department of Health Policy and Administration, College of Public Health, University of the Philippines Manila \\ ${ }^{3}$ Research Division, Health Policy Development and Planning Bureau, Department of Health, Manila, Philippines Manila
}

\begin{abstract}
Background and Objective. Research plays an important role in generating new knowledge that could improve health outcomes when translated into action. As such, there must exist a supportive research policy environment that facilitates the provision of necessary resources and sustainably ensures an appropriate number of skilled researchers buttressed by institutions. These, in turn, are envisioned to provide facilities, information systems, financial grants, and avenues for career development and collaboration. This study aims to analyze factors in the current policy environment that makes health research possible in the Philippines.
\end{abstract}

Methods. Qualitative exploratory design was used to characterize the Philippine health research environment. Guided by Adamchak's framework on policy environment, a content review of 39 policy documents (1991 to 2018) by the four core agencies of the Philippine National Health Research System was conducted. Seven elements of the policy environment were described.

Results. The policies analyzed in this study mainly addressed the legal, political, cultural, economic, and ecological elements of the policy environment. Policies that support the demographic and technological elements are lacking, in that these leave out details that are essential for capacity building and use of research output. A cross-cutting effort to resolve gaps may be necessary.

Conclusion. Several factors continuously affect the environment in which policy is developed. There is room for improvement in terms of showcasing the government's regulatory quality and independence from political pressure. Equal attention must also be paid to human capital development, innovation partnerships, and mechanisms to improve knowledge impact, absorption, and utilization.

Key Words: health policy research, policy environment, policy research

\section{INTRODUCTION}

Research plays an important role in generating new knowledge that could improve health outcomes when translated into action. In the pursuit of understanding how health can be better achieved, approaches to health research have evolved, which may be broadly categorized into biomedical research and health policy and systems research (HPSR). Biomedical research aims to understand normal and abnormal functions using biological samples and patient

Corresponding author: Jaifred Christian F. Lopez, MD, MPM Alliance for Improving Health Outcomes records to develop new therapies, drugs and devices that improve diagnostics and treatment. ${ }^{1,2}$ Meanwhile, HPSR 62 West Avenue, Quezon City 1104, Philippines

Telephone: +6322947808

Email: jaifredlopez@gmail.com is defined as a research field that "seeks to understand and improve how societies organize themselves in achieving 
collective health goals, and how different actors interact in the policy and implementation processes to contribute to policy outcomes." ${ }^{3}$ The key difference between the two is in how these investigate factors that affect individual and population health: biomedical research utilizes laboratory techniques for drug and technology development, ${ }^{2}$ while HPSR investigates structural factors of health interventions, including the vital functions of health systems: service provision, resource generation, financing, and stewardship..$^{3-7}$ Nonetheless, it is also acknowledged that these two categories represent ends of a thematic spectrum, between which there may be significant overlaps.

Both biomedical research and HPSR are heavily reliant on available and accessible sources of funding, which allows for the procurement of facilities, hiring of personnel, and dissemination of research output. ${ }^{8-9}$ In particular, biomedical research is dependent on the availability of instruments, facilities, and equipment. ${ }^{2}$ On the other hand, HPSR requires expenses for travel, representation, and other activities that would be critical for stakeholder participation and field data collection. ${ }^{10}$ Because of limited resources in low- and middle-income countries (LMICs), implementing such research approaches and sustaining productivity remains a significant challenge. ${ }^{11}$ To address resource constraints in LMICs, several international institutions have initiated global health programs that aim to support and fund health research in developing countries. Grepin et al. reports that between 2000 and 2014, international donors donated a total of US $\$ 246$ billion to fund HPSR in developing countries. ${ }^{12}$ While the success of these initiatives are encouraging and have increased the supply of resources, these efforts seem to be insufficient in stimulating research productivity. ${ }^{12}$ In particular, a report by the Alliance for Health Policy Systems Research notes that failure in health research, specifically HPSR, may be largely attributed to inefficiencies in resource allocation due to poor leadership and management. ${ }^{3}$

Studies have been conducted to determine factors that are important in health research productivity. From the university perspective, a 2017 Uganda study on research productivity by Nakanjanko et al. noted that in increasing research productivity among faculty, the following needs were identified:

1. Need for an institutionally-led structured faculty career development program,

2. Skills-building in research methods and scientific writing,

3. Protected time for research-related activities,

4. Opportunities for collaborative research, and

5. Individual development planning and time management. ${ }^{13}$

In achieving these needs, Nakanjanko and colleagues recommended that "structured institutional support" is critical. In the Philippines, these factors were validated by
Mantikayan and Abdulgani, which are 1) individual factors, such as self-efficacy, affiliation, motivation, commitment, and research skills; 2) institutional factors, such as staff support, resources, incentives, and career development; 3) leadership factors, such as reputation in the field; and 4) ascriptive factors, which include age and gender, level of perceived intelligence and the personality of the individual. ${ }^{14}$

A supportive policy environment should facilitate the provision of necessary resources and sustainably ensures an appropriate number of skilled researchers supported by organized institutions, which are able to provide facilities, information systems, financial grants, and avenues for career development and collaboration., ${ }^{3,10,11,15}$ Presence of supportive policies for health research is particularly critical. Health research, especially those that do not directly result to private profit could not grow without government support. This is a characteristic of a public good where a strong and appropriate policy environment is necessary such that populations could benefit from high quality knowledge generation.

There is a recognized need in the Philippines to grow the body of evidence that could support policy making. This type of health research requires a conducive policy environment. This review aims to characterize the current policy environment in the Philippines. The review can provide vital information on how to strengthen health research in the country. In response to this knowledge gap, this paper explores the policy environment of health research in the Philippines in the lens of Adamchak's policy environment framework. Originally a framework assessing the policy environment influencing population programs, it is a relatively safe and versatile framework for a pilot analysis of factors affecting health research owing to its simplicity of identifying components without assuming any interactions between them. Adamchak identifies seven elements to assess policy environment in health programs: legal, political, economic, demographic, ecological, cultural and

Table 1. Adamchak's elements of policy environment ${ }^{16}$

\begin{tabular}{ll}
$\begin{array}{l}\text { Policy } \\
\text { Environment }\end{array}$ & $\begin{array}{l}\text { Description } \\
\text { Legal }\end{array}$ \\
Political & $\begin{array}{l}\text { Establishes the operating conditions for agencies } \\
\text { which may range from prohibition to regulation } \\
\text { Support for health research such as political } \\
\text { commitment, government action, political pressures, } \\
\text { international politics and institutional and political } \\
\text { venues for communication among policymakers }\end{array}$ \\
Economic & $\begin{array}{l}\text { Resource concerns such as allocation of budget, } \\
\text { priority setting and household income }\end{array}$ \\
Demographic & $\begin{array}{l}\text { Data and information system relevant in conducting } \\
\text { health researches }\end{array}$ \\
Ecological & $\begin{array}{l}\text { The local and international interactions and } \\
\text { relationships of a core agency } \\
\text { Local norms, morals and beliefs }\end{array}$ \\
Technological & $\begin{array}{l}\text { Developments surrounding science, technology and } \\
\text { engineering, research and practice }\end{array}$ \\
\hline
\end{tabular}


Policy Environment for Philippine Health Research

technological (Table 1). ${ }^{16}$ The legal environment determines the domain upon which health systems research can operate. This includes regulations and prohibitions that dictate directions and actions for the national health research systems. Adamchak cites political commitment, government action, political pressures, and international politics as influencers in the political environment of health research. Economic environment refers to the allocation of human, financial, and infrastructure resources, priority setting, and household income. The demographic environment is critical in setting the policy environment of a country because of its influence in political decision-making. Similarly, local norms, morals, and beliefs characterize the cultural environment and can influence decisions of policymakers. Ecological environment refers to the social ecology in a country such as collaboration and alliances between public, private, and international institutions. Finally, scientific discoveries, technological advances, research capacity, and knowledge utilization constitute the technological environment and can trigger changes in policy directions.

The study aims to examine the content of policies governing health research in the Philippines, on how these map out across the policy environment components of Adamchak's framework. This mapping will provide an overview of the strengths in the current policy environment. It will also identify what the gaps are, that could be target for program strengthening.

\section{METHODS}

Qualitative exploratory design was used to characterize the Philippine health research environment. Guided by Adamchak's framework on policy environment, a content review of 39 policy documents (1991 to 2018) by the four core agencies of the Philippine National Health Research System was conducted.

\section{Search strategy}

Policies deemed relevant to the framework were retrieved through a search in the websites of the four core agencies of the Philippine National Health Research System (PNHRS), Department of Health (DOH), National Institutes of Health (NIH), and Commission on Higher Education (CHED), using the terms "health policy and systems research" and "health research". Grey literature was searched using the same key words through internet search engines (Google and Google Scholar). Issuances of the Philippine Council for Health Research and Development and the certifications and manuals were chosen for analysis. Department of Science and Technology (DOST) was excluded from analysis, with the exception of issuances that were re-issued within the DOH or CHED, and in the case of two laws, the PNHRS Act (Republic Act 10532), and the Magna Carta for Scientists, Engineers, Researchers, and other Science \& Technology Personnel (Republic
Act 8439). Calls for research proposals and event-specific announcements which may have been disseminated in the concerned agencies as internal issuances were also excluded. All results of the search are listed in Table 2.

\section{Analysis}

The authors analyzed the contents of the document review by identifying prevailing themes that correspond to the elements of policy environment as identified and defined by Adamchak. The themes were then categorized whether they fulfill the legal, political, economic, demographic, ecological , cultural or technological element of the policy environment for health research.

Themes that emerged from the review were validated through key informant interviews of four personnel representatives, one each from PCHRD, DOH, CHED, and NIH. The authors gathered insights, perceptions, and awareness on the policies and plans supporting health research in the country. Additional information and context arising from the interviews regarding the documents were used for triangulation.

The study was given ethical clearance by the St. Cabrini Medical Center-Asian Eye Institute Ethics Review Committee.

\section{RESULTS}

The search strategy yielded a total of 39 policies (Table 2): two republic acts (RA), one implementing rules and regulations (IRR), two administrative orders (AOs), six department orders (DO), two department circulars (DC), one department memorandum (DM), three memorandum circulars (MC), 15 CHED memorandum orders (CMO), three certifications, and four others, specifically a research agenda document, a citizen's charter, an implementing details document, and a compilation of grant policies.

Table 3 shows the salient features observed in each policy environment across all the 39 policies reviewed.

Policies categorized under the legal environment were observed to require that governance and efforts adhere to the national health policy and standards, national strategic plan for health development, and policy and strategic documents for research development. Moreover, there were regulations that were noted to ensure good governance, as these enumerated legal obligations of agencies, committees, other relevant stakeholders and of individual officials. Meanwhile, the country's political environment policies were seen to emphasize advocacy such as those that encourage efforts to address national health system needs and meet international standards and expectations such as the United Nations Millennium Development Goals and the World Health Organization's Building Blocks of Health Systems.

Additionally, many of the policies reviewed were observed to be economic in nature such as the formulation of health research priorities, their strict implementation, and 
Policy Environment for Philippine Health Research

Table 2. Policies included in the analysis

\begin{tabular}{|c|c|}
\hline Issuance No. & Title \\
\hline RA 10532 & PNHRS Act and its IRR \\
\hline RA 8439 & Magna Carta for Scientists \\
\hline \multicolumn{2}{|c|}{ Department of Health } \\
\hline AO 104-A s.1991 & The Essential National Health Research Program \\
\hline DC 2017-0357 & $\begin{array}{l}\text { Adoption of Joint DOST-DOH-CHED-UPM Administrative Order no. } 001 \text { "Implementation of the Philippine National } \\
\text { Health Research System Monitoring System" }\end{array}$ \\
\hline DC 2014-0066 & Guidelines for the Philippine Health Research Ethics Board \\
\hline DM 2014-0389 & Assumption to Duty of Employees Re-appointed to Positions based on the NOSCA under EO 366 \\
\hline DO 2012-0197 & Establishment of a Research Reference Hub in the Department of Health \\
\hline DO $2012-5221$ & Creation of an Executive Board of the Establishment of a Reference Hub in the Department of Health \\
\hline DO 2014-0044 & Revised Guidelines on the Development and Implementation of Technical Assistance at the Department of Health \\
\hline DO 2014-0171 & Guidelines on the Implementation of Health Researches in the Department of Health \\
\hline DO 2015-1744 & Composition of the Reference Executive Board of the Department of Health \\
\hline DO 2018 (DRAFT) & $\begin{array}{l}\text { Omnibus Implementing Guidelines on Enabling Health Research and Supporting Evidence to Policy Translation in the } \\
\text { Department of Health and its Attached Agencies }\end{array}$ \\
\hline MC 2013-0043 & $\begin{array}{l}\text { Joint Memorandum Order 2012-001 (DOH, DOST, CHED, UPM) on requirements for ethical review of health research } \\
\text { involving human participants }\end{array}$ \\
\hline MC 2007-0035 & $\begin{array}{l}\text { DOST Administrative Order no.001 s. } 2007 \text { "Requirements for ethical review of health research involving human } \\
\text { participants }\end{array}$ \\
\hline MC 2007-0045 & $\begin{array}{l}\text { Proclamation No. } 1309 \text { "Declaring Every Second Week of August as the Philippine National Health Research System } \\
\text { Week" }\end{array}$ \\
\hline HPDPB Mandate & HPDPB Vision and Mission Organizational Structure \\
\hline
\end{tabular}

Commission on Higher Education

CMO no. 47, s. 1996 Policies on Research Priorities for Funding by the Higher Education Development Fund and Guidelines and/or Procedures in the Availment Thereof

CMO no. 30, s. 1998 Implementing Guidelines for CHED Research Grants

CMO no. 25, s. 1998 Amendments to CMO no. 47 s. 1996

CMO no. 15, s. 1998 Launching of the National Higher Education Research Agenda, 1998-2007

CMO no. 40 s. 1998 Research Advocacy on Higher Education

CMO no. 21 s. 1999 Strengthening Research Advocacy in Higher Education Through the Philippine Association of Graduate Education

CMO no. 08, s. 2000 Selection of the Zonal Research Centers

CMO no. 13, s. 2003 Guidelines for CHED Visiting Research Fellowships

CMO no. 32, s. 2004 Addendum to CMO no. 13 s. 2003

CMO no. 34 s. 2007 Policy Requirement in the Conduct of Health Research Involving Human Subjects/Participants

CMO no. 49, s. 2007 Updates of the Data/Information Collection on Research for the Research Management Information System from CY 2005 to 2006

CMO no. 38, s. 2008 Revised Guidelines for the Operation of the Zonal Research Centers

CMO no. 42 s. 2009 Implementing Rules and Regulations for CMO no. 13 s. 2009 "Guidelines for CHED Accreditation of Research Journals and Providing Incentives Therefor"

CMO no. 3, s. 2015 Policy Reforms for the Grants-in-Aid Funds of the Commission on Higher Education (CHED) for Research and Development, and Extension

CMO no. 52, s. 2016 Pathways to Equity, Relevance and Advancement in Research, Innovation and Extension in Philippine Higher Education National Higher Education Research Agenda 2 (2009-2018)

Philippine Council for Health Research and Development (Department of Science and Technology)

Joint AO on the Philippine Health Information Exchange (with the Department of Health and the Philippine Health Insurance Corporation)

Citizens Charter

Certifications Anti-Red Tape Act Compliance Certification

PhilGEPS Certification

Transparency Seal Certification

Implementing Details of the Freedom of Information Executive Order

National Institutes of Health, UP Manila

Grant Policies (for NIH researchers) 
Policy Environment for Philippine Health Research

Table 3. Salient features of policies reviewed, according to policy environment element (after Adamchak, 1997)

\begin{tabular}{|c|c|}
\hline $\begin{array}{l}\text { Policy } \\
\text { Environment }\end{array}$ & Salient Features from Policy Documents Included in the Analysis \\
\hline Legal & $\begin{array}{l}\text { - Emphasis on adherence to the national strategic plans for health development, research development } \\
\text { - Emphasis on "good governance," "transparency," and "accountability." } \\
\text { - Institutionalization of a coordinating body for health research (PNHRS) } \\
\text { - Provisions on the responsibilities of individual agency members of PNHRS }\end{array}$ \\
\hline Political & $\begin{array}{l}\text { - Policies stress importance of national health research production that addresses health needs } \\
\text { - Importance of ensuring that investments yield maximal benefit on people's lives } \\
\text { - Push on institutions to align with international standards of productivity and global competitiveness in research capacity } \\
\text { - Mandating of coordination within and among government agencies }\end{array}$ \\
\hline Economic & $\begin{array}{l}\text { - Formulation of health research priorities } \\
\text { - Mandating of funding allocations and incentives } \\
\text { - Ensuring sustainability of research funds } \\
\text { - Creation of research grants }\end{array}$ \\
\hline Demographic & - Data/information exchange and sharing between educational and research institutions, government, and industry \\
\hline Ecological & $\begin{array}{l}\text { - Creation of a consultation framework for stakeholders in health research, primarily for setting health research priorities } \\
\text { - Framework for collaboration between individual stakeholders, experts, and public and private institutions and organizations } \\
\text { - Framework for dissemination of research results } \\
\text { - Attempts to institutionalize demand generation mechanisms }\end{array}$ \\
\hline Cultural & $\begin{array}{l}\text { - Health research ethics capacity building } \\
\text { - Mandating adherence to ethical principles and guidelines }\end{array}$ \\
\hline Technological & $\begin{array}{l}\text { - Capacitating health researchers } \\
\text { - Research utilization }\end{array}$ \\
\hline
\end{tabular}

ensuring sustainable resources for health research through collaboration and coordination between and among public and private stakeholders. Furthermore, policies surrounding the ecological environment were noted to focus on demand generation, such as conducting an inclusive and participative stakeholder consultation to systematically assess the needs of the health systems thereby identifying research needed to address such gaps and an effective dissemination of these priorities. In addition, cultural policies were seen to focus on well-informed and trained researchers that adhere to the accepted ethical principles and guidelines. Finally, demographic policies were noted to focus on facilitating access to already existing research data. This includes technological policies on training health researchers and utilizing research outputs. However, descriptions on how to conduct these training activities and the utilization of research outputs were not seen in the policies reviewed.

\section{DISCUSSION}

Defining the policy environment aims to specify a wide range of indirect or direct factors that affect health research. ${ }^{15}$

The legal environment was found to be relatively light-handed in setting goals and assigning responsibilities to facilitate research. Our results showed that this refers mainly to alignment of research efforts to national research priorities, plans, and standards, as well as the enumeration of legal obligations of various stakeholders. Since the effectiveness of laws and policies depends on the extent the rule of law prevails and the ability of government to implement sound policies that permit and promote research and development, it is thus recommended that regulations should be strengthened. ${ }^{17,18}$ Similarly, consideration must also be equitably given to current laws in place and customary law derived from ethical, ethnic, and cultural traditions. ${ }^{19}$

Aside from a legal environment that ensures all concerns are covered, government action is a recognized as one of the main facilitators for achieving policy goals. ${ }^{20}$ Studies have shown that political support of policies becomes more important as the social circumstances becomes less conducive to the policy being proposed..$^{21}$ In LMICs, political actions carry more immediate impact than their developed counterparts due to their increased insulation and intrusive role in the economy. ${ }^{16}$ The policies analyzed in this study articulate support through the encouragement of efforts to address health system needs and meet international standards. Political solutions are often proposed by stakeholders closest to government, with political costs and benefits often more influential to decisionmaking than analytic evaluations of an issue. ${ }^{22,23}$ In this case, the government must show a degree of independence from political pressures as well as credibility of its commitment to health research policies, an assessment that may require consensus building and a common desire for researchguided development. ${ }^{18}$

Furthermore, the economic environment must be reviewed as it is the basis through which policy and research efforts are justified. A country's economic state defines 1) the competition for resources, 2) allocation of human, financial, and infrastructure resources, and 3) agendasetting. ${ }^{16}$ The policies reviewed in this study considered the economic policy environment through the formulation of health research priorities, their strict implementation, and ensuring sustainable resources for research. In crafting 
health research policies that considers the economic environment, attention must also be paid to human capital development, the strength of the private sector, the extent of innovation linkages, labor migration patterns, and level of donor assistance. ${ }^{16,18}$

Moreover, the ecological environment refers to the number of local and international organizations that a focal organization has built relationships with. ${ }^{16}$ Alliances and partnerships with international organizations may shape the policy development of a country. ${ }^{16}$ In the Philippines, ecological research policies are focused on demand generation, inclusive and participative consultation process to assess health system needs, and effective dissemination of research priorities. Besides active participation of a country in regional or international bodies and declarations from international meetings, the following ecologic influences must also be considered: 1) the extent the government is willing to explore policies and strategies implemented by other countries, 2) the role that non-governmental organizations play in promoting research and the nature of their collaboration with government, and 3) the influence of bilateral or multilateral donor and lending institutions over domestic policies. ${ }^{16}$

Meanwhile, cultural influences in a policy environment are difficult to measure as values, beliefs, norms, and morals change over time. ${ }^{16}$ The Philippines has implemented policies that mandate adherence to ethical principles guidelines as well as increasing health research ethics capacity. The cultural environment policy-makers live in affect their development of strategies and overlooking local health needs and priorities often results in their non-inclusion in national research priorities or policies. ${ }^{16,22}$ Policy-makers must consider norms, beliefs, media, and other cultural influences when crafting policies. In particular, they should assess the population's access and openness to outside knowledge and desire for improved living conditions fostered through awareness of conditions in other societies. ${ }^{19,20,24}$

In addition, the technological environment is concerned with developments and changes as a result of research. These may be measured as high-tech imports, development of new business and organizational models, research talent in enterprises, and intellectual property payments. ${ }^{18}$ The policies analyzed focused on training health researchers and utilizing research outputs. The mechanisms for these were unclear in the policies analyzed. Utilization and absorption of research may be improved through online awarenessraising campaigns, which requires a functioning government online service and an e-participation system that facilitates online information sharing, consultations, and engagement in decision-making processes. ${ }^{16,18}$

Finally, the country's demographic policies focus on access to and information sharing of existing research data. However, mechanisms to facilitate these processes were unclear in the policies analyzed. Stakeholders, particularly policy-makers, should have access to timely, context- sensitive, and relevant data to increase its role in decisionmaking. In LMICs, evidence-based decision-making is hindered by challenges in accessing existing evidence, capacity to appraise evidence, and incentive structures that prioritize publication over policy implication of research. ${ }^{25}$

In closing, this assessment pinpoints the need for strategies that will help strengthen the policy environment for health research. Developing these strategies will involve the concerted effort of stakeholders and agencies, who are all convinced of the need to purposefully allocate resources for research. Often, this will require seizing an optimal opportunity to develop a policy intervention, dubbed as a "policy window", that can only be opened in the context of shared decision-making and agenda-setting. These, in turn, can only be possible if issues and concerns in the political stream (e.g. national mood, public opinion), policy stream (e.g. assessments recommended by technical experts), and problem stream (e.g. matters requiring active intervention). ${ }^{26}$ These processes may be facilitated through continued improvement of information technology, that enables communication despite the unique geography of the country. But, to promote involvement in these discussions, the government and institutions engaged in research should also be given the capacity to provide incentives to researchers and other key stakeholders.

\section{CONCLUSION AND RECOMMENDATIONS}

This review suggests that the country's policy documents aim to address all factors of the policy environment for health research. Particularly, the policies analyzed in this study mainly addressed legal, political, cultural, economic, and ecological elements. However, there is room for improvement in the aforementioned elements in terms of showcasing the government's regulatory quality and independence from political pressure. Equal attention must also be paid to human capital development, innovation partnerships, and multi-sectoral collaborations.

Meanwhile, policies that support the demographic and technological elements leave out details that are essential for capacity building and use of research output. While there are existing policies to improve health information exchange and sharing between institutions and among researchers, there were no provisions to expand health information systems and improve the analysis and synthesis of data for better communication and use. This leads to low research utilization due to the decision-makers' difficulty in accessing research outputs to guide in evidence-based policymaking. Thus, strategies that may improve knowledge impact, utilization, and absorption include: 1) online awareness campaigns, 2) an e-participation system for stakeholders used for information sharing, consultations, and engagement in decision-making process, and 3) changing incentive structures in the academic sector to prioritize research policy impact. 


\section{Acknowledgment}

We gratefully acknowledge the inputs of Prof. Marilyn Ellorin-Crisostomo of the University of the Philippines, Manila, and the helpful suggestions of the peer reviewers.

\section{Statement of Authorship}

All authors approved the final version submitted.

\section{Author Disclosure}

All authors declared no conflicts of interest.

\section{Funding Source}

This paper was funded by the Philippine Council for Health Research and Development.

\section{REFERENCES}

1. Indrayan A. Elements of medical research. Indian J Med Res. 2004 Mar; 119(3):93-100

2. Fauci AS. New and reemerging diseases: the importance of biomedical research. Emerg Infect Dis. 1998 Jul-Sep; 4(3):374-8. doi: 10.3201/ eid0403.980308

3. Mills A, Bennett S, Bloom G, Gonzalez-Block M, Pathmanathan I. Strengthening health systems: the role and promise of policy and systems research [Internet]. Geneva: Global Forum for Health Research; 2004 [cited 2019 Feb]. Available from: https://www.who. int/alliance-hpsr/resources/Strengthening_complet.pdf.

4. World Health Organization. The World Health Report 2000: Health Systems: Improving Performance [Internet]. Geneva: World Health Organization; 2000 [cited $2019 \mathrm{Feb}$ ]. Available from: https://www. who.int/whr/2000/en/whr00_en.pdf?ua=1.

5. Roemer MI. Health system financing by social security. Int J Health Plann Manage. 1987 Apr-Jun; 2(2):109-24. doi: 10.1002/ hpm.4740020205.

6. Gilson L. Health Policy and Systems Research: A Methodology Reader [Internet]. Geneva: World Health Organization; 2012 [cited 2019 Feb]. Available from: https://www.who.int/alliance-hpsr/ alliancehpsr_reader.pdf.

7. Remme JH, Adam T, Becerra-Posada F, Darcangues C, Devlin M, Gardner C, et al. Defining research to improve health systems. PLoS Med. 2010 Nov 16; 7(11):e1001000. Published online 2010 Nov 16. doi: 10.1371/journal.pmed.1001000.

8. Mandal J, Parija M, Parija SC. Ethics of funding of research. Trop Parasitol. 2012 Jul; 2(2):89-90. doi: 10.4103/2229-5070.105172.

9. Pratt B, Paul A, Hyder AA, Ali J. Ethics of health policy and systems research: a scoping review of the literature. Health Policy Plan. 2017 Jul 1; 32(6):890-910. doi: 10.1093/heapol/czx003.

10. World Health Orgnization. Changing Mindsets: Strategy on Health Policy and Systems Research [Internet]. Geneva: WHO; 2012 [cited 2019 Feb]. Available from: https://www.who.int/alliance-hpsr/ alliancehpsr_changingmindsets_strategyhpsr.pdf.

11. Stearns B, editor. Equitable access: research challenges for health in developing countries [Internet]. [cited 2019 Apr]. Available from: http://announcementsfiles.cohred.org/gfhr_pub/assoc/s14796e/ s14796e.pdf.
12. Grépin KA, Pinkstaff CB, Shroff ZC, Ghaffar A. Donor funding health policy and systems research in low- and middle-income countries: how much, from where and to whom. Health Res Policy Syst. 2017 Aug 31; 15(1):68. doi: 10.1186/s12961-017-0224-6

13. Nakanjako D, Akena D, Kaye DK, Tumwine J, Okello E, Nakimuli A, et al. A need to accelerate health research productivity in an African University: the case of Makerere University College of Health Sciences. Health Res Policy Syst. 2017 Apr 21; 15(1):33. doi:10.1186/s12961017-0196-6

14. Mantikayan J, Abdulgani M. 7th International Conference on Multidisciplinary Research. In: JPAIR Multidisciplinary Research [Internet]. 2018 [cited 2019 Feb] Vol 31. PAIR; 2017. Available from: https://www.researchgate.net/publication/321747577_Factors_ Affecting_Faculty_Research_Productivity_Conclusions_from_a_ Critical_Review_of_the_Literature.

15. Bennett S, Frenk J, Mills A, English K, Govender V, Grepin K. World report on health policy and systems research [Internet]. Geneva: WHO; 2017 [cited 2019 Feb]. Available from: https://apps. who.int/iris/bitstream/handle/10665/255051/9789241512268-eng. pdf? sequence $=1$.

16. Adamchak S. Assessing the Policy Environment: What influences population policy? Population Technical Assistance Project [Internet]. 1997 [cited 2018 Sept]. Available from: http://www.policyproject.com/ policycircle/documents/regulationsAndPolicyIssues.pdf.

17. Gibson J, Ivancevich J, Donnelly J, Konopaske R. Organizations: Structures, Processes and Outcomes, 14th edition. Englewood Cliffs, NJ: Prentice-Hall; 2009. pp. 300-9.

18. United Nations Conference on Trade and Development. A Framework for Science, Technology and Innovation Policy Reviews [Internet]. Geneva, Switzerland: UN; 2011 [cited 2019 Feb]. Available from: https://unctad.org/en/Docs/dtlstict2011d7_en.pdf.

19. Teubner G, Fischer-Lescano A. Cannibalizing epistemes: will modern law protect traditional cultural expressions? In: Grabe $\mathrm{CB}$, BurriNenova M. Traditional cultural expressions in a digital environment. Cheltenham: Edward Elgar; 2008. pp.17-19.

20. Woolcock M, Narayan D. Social capital: Implications for development theory, research, and policy. World Bank Res Obs. 2000; 15(2):225-49.

21. Barrett D, Tsui AO. Policy as symbolic statement: International response to national population policies. Soc Forces. 1999;78(1):213-33.

22. Chilaka MA, Nwaneke PK. Integrating corporate social responsibility, health improvement, and community support in development programmes: a case for enhancing the application of health impact assessment in programme implementation in the Niger Delta region. Local Environ. 2016;21(3):383-95.

23. Bernstein $\mathrm{S}$. The changing discourse on population and development: Toward a new political demography. Stud Fam Plann. 2005 Jun; 36(2):127-32.

24. Atkinson MM, Coleman WD. Policy networks, policy communities and the problems of governance. Governance. 1992;5(2):154-80.

25. Shroff ZC, Javadi D, Gilson L, Kang R, Ghaffar A. Institutional capacity to generate and use evidence in LMICs: current state and opportunities for HPSR. Health Res Policy Syst. 2017 Nov 9; 15(1):94.

26. Beland D, Howlett M. The role and impact of the multiple-streams approach in comparative policy analysis. J Comp Policy Anal Res Pract. 2016; 18(3):221-27. doi: 10.1080/13876988.2016.1174410. 